\title{
From older to younger: intergenerational promotion of health behaviours in Portuguese families affected by familial amyloid polyneuropathy
}

\author{
Carla Roma Oliveira ${ }^{1,2}$, Álvaro Mendes ${ }^{3}$ and Liliana Sousa ${ }^{\star, 4}$
}

The role of older generations in families with hereditary diseases has been recognised and associated to their function as guardians of the family's medical history. However, research is scarce in examining the roles that older generations play in terms of health promotion and risk management towards younger generations, which is particularly evident with incurable genetically inherited disorders such as familial amyloid polyneuropathy (FAP) ATTR Val30Met. This qualitative exploratory study examines the roles that older generations play towards younger generations, in terms of health promotion and risk management, in families with FAP. It also explores the intergenerational flow by analysing who from the older generation plays what role(s) towards whom from the younger generation. This study adopts the critical incidents technique. The sample comprises 18 participants that reported 76 critical incidents. The interviews were audio-taped and submitted for content analysis with the main findings suggesting four roles performed by the older family members towards the younger ones: modelling, encouraging, informing and supporting. The intergenerational flow takes place mostly between women, from mother to daughter, and from older affected individuals to young pre-symptomatic carriers. The older generations can be involved in the clinical practice as partners in supporting younger relatives in families with FAP. Clinical genetic services and the health-care system more broadly might want to consider these roles and the intergenerational flow of support so that this information can be used to maximise health promotion behaviours in at-risk families.

European Journal of Human Genetics (2017) 25, 687-693; doi:10.1038/ejhg.2017.40; published online 22 March 2017

\section{INTRODUCTION}

Transthyretin-related amyloid familial amyloid polyneuropathy (FAP), also known as Paramyloidosis, is an autosomal-dominant neurodegenerative disorder; Val30Met is the most common disease-related variant. ${ }^{1}$ Symptoms are highly incapacitating including progressive sensory impairment, with neuropathic pain or numbness in the hands and feet, and a reduction in fine motor skills. FAP has a high lifelong penetrance and its age of onset occurs mainly between the ages of 25 and 35 years, but this can vary greatly. Non-curative therapeutic measures that slow down the progress of symptoms in affected carriers are available, such as liver transplantation and oral medication. ${ }^{1}$ FAP has been initially described by Andrade ${ }^{2}$ in Portugal, where it has the largest cluster of patients worldwide. The disease occurs worldwide, but it is endemic in some regions, most notably northern Portugal (Póvoa de Varzim and Vila do Conde), where FAP was initially found and where its incidence ${ }^{3}$ may reach 163 in 100000.

In Portugal, pre-symptomatic genetic tests (PST) for at-risk individuals has been possible through biochemical testing since 1984 (later through a molecular genetic test); genetic counselling and psychosocial support are provided at some genetic services, and community-based genetic counselling has been offered ${ }^{4}$ since 1986. Preimplantation genetic diagnosis is available in Portugal ${ }^{5}$ since 2000. Carriers of the pathogenic variant are offered regular clinical monitoring to detect early signs of the disease and, therefore, maximise the effectiveness of the available non-curative treatments. ${ }^{1}$ The disclosure of disease risk information to at-risk relatives is key to obtaining the full benefits of genetic health care. ${ }^{6}$ The sharing of such information can be crucial for their health management, but also in terms of lifeplanning issues, including employment, lifestyle and reproduction choices. Therefore, the promotion of risk management behaviours is key in the health of members of FAP families.

Previous studies have evidenced the importance of the supportive and informational role played by family members in facilitating the engagement in health promotion strategies and at-risk management behaviours among other relatives, and in influencing decisions about genetic screening and testing. ${ }^{7-10}$ In addition, research has suggested that at-risk individuals who do not discuss risk factors with family members are less likely to engage in recommended cancer surveillance. ${ }^{9,11}$

Regarding older family members, literature has portrayed them as a critical source of family health information and important suppliers of emotional support and affection to younger generations. ${ }^{12,13}$ The role of older generations in families with hereditary diseases has been recognised and is predominantly attached to their function of guardians or gatekeepers of the family's medical history; ${ }^{14}$ this is so given their presumed privileged knowledge about illness-related information of ancestor members of the family to whom access is often not available (due to death or incapacity). However, literature is

\footnotetext{
${ }^{1}$ Department of Medical Sciences, University of Aveiro, Portugal; ${ }^{2}$ Associação dos Lares Ferroviários, Entroncamento, Portugal; ${ }^{3}$ i3S-—Instituto de Investigação e Inovação em Saúde; IBMC_-Institute for Molecular and Cell Biology, UniGENe and Centre for Predictive and Preventive Genetics (CGPP); Universidade do Porto, Porto, Portugal; ${ }^{4}$ Department of Education and Psychology, Center for Health Technology and Services Research (CINTESIS), University of Aveiro, Aveiro, Portugal

*Correspondence: Dr CR Oliveira, Associação dos Lares Ferroviários, Rua dos Ferroviários, Casal Saldanha, 2330-144 Entroncamento, Portugal.

Tel: +351 912 733183; Fax: +351 234 370640; E-mail: carlaromaoliveira@ua.pt

Received 22 October 2016; revised 31 January 2017; accepted 21 February 2017; published online 22 March 2017
} 
rather scarce in reporting other roles of older generations regarding health promotion and risk management towards younger generations. In later life, older persons often wish to provide for future generations (generativity), which makes their involvement, in the health management of younger generations, foreseeable. ${ }^{15,16}$ Indeed, recent research has examined what roles older generations play in terms of health promotion and risk management towards younger generations, and has mainly focused on conditions to which susceptibility genetic tests and preventative treatment options are available, such as hereditary cancers, diabetes or heart disease. These studies have shown that members from older generations are likely to act as screening encouragers and facilitators in the transmission of self-care knowledge for younger generations. ${ }^{17,18}$ Yet, to the best of our knowledge, there is no research exploring these roles in incurable and highly incapacitating genetically inherited conditions where PST are available, such as FAP. Therefore, the aim of this exploratory study is to examine the roles that members of older generations play towards younger generations, in terms of health promotion and risk management, in families with FAP; and to explore the intergenerational flow by analysing who from the older generation (gender, kinship and disease status) plays what role(s) towards whom from the younger generation (gender, kinship and disease status). The results of this study contribute to better understand the role of the older generation in families affected by genetically inherited disorders for which no curative treatments are available; contribute to the awareness of how the intergenerational promotion of health flows within these families; and to understand how the older family members can be further involved as partners at the clinical practice level.

\section{METHODS}

This exploratory qualitative study is based on the critical incidents technique, which is a method that allows the collection of events that reveal life meaningful experiences by using the perspectives of those involved in the event, thus having access to the individual perspective of significant roles. ${ }^{19}$ An incident is an observable human activity and incidents typically include a description of the key players and the outcomes. A critical incident may be a commonplace, everyday event or interaction, but it is 'critical' in that it stands for the one who lives it. ${ }^{20}$ critical incidents technique has been widely used to examine the relations between health professionals and users. ${ }^{21,22}$ And more recently to analyse the intergenerational transmission of gynaecologic information. ${ }^{23}$

\section{Procedures}

This study was approved by the IBMC Human Ethics Committee. The sample was intentional and non-probabilistic. The recruitment was mediated by the national FAP patient's association (APP), that was contacted directly, and a meeting was scheduled to present the study and explain the needed collaboration. Moreover, APP accepted to collaborate by making the study known to their associates and by mediating the contact between potential participants and the researchers. The inclusion (members of families with a history of FAP, $\geq 18$ years, oriented in time and space) and exclusion criteria (having a mental or psychological disease, substance abuse, in critical clinical situation that might limit consent) were indicated. To those potential participants that showed interest in participating, APP was authorised to provide the contact details (e-mail address or mobile telephone number) of the researchers. The other possibility was to have APP send the contact information of the potential participants by e-mail to the researchers who then established direct contact with the subjects. This procedure was complemented by snow-ball sampling, that is, after the interview the researcher asks the participant to identify other potential participant(s) and to mediate that contact. So, the first contact with potential participants was done via a telephone call by the first author who explained the objectives of the study, and its methods, in detail and requested the individuals' collaboration. After this initial contact, all of the identified persons agreed to participate and the interviews were scheduled (date and time) taking into account the participants' convenience. The verbal consent was obtained and audio-recorded.

\section{Instrument}

The collection of data was performed by the first author and the critical incidents technique was administered based on a semi-structured schedule and executed via telephone interviews. The interview was introduced with the following invitation:

'Please think about one or more episodes that have occurred in your family, and that you have observed or participated in, involving a person from the older generation and a person from the younger generation. Think about episodes that have been significant and meaningful for you and/or for members of the younger generation in your family in terms of how FAP is dealt with and managed by individuals and by the family as a whole. Think about events that you remember clearly. Please indicate your role in the event: observer, member of the younger generation or member of the older generation.'

Table 1 Participants

\begin{tabular}{|c|c|c|c|c|c|}
\hline Participant (narrator) & Age & Gender & Disease status & Kinship among participants & Number of incidents \\
\hline P1 & 46 & Male & Affected (liver transplantation) & Non & 4 \\
\hline P2 & 41 & Female & Affected (liver transplantation) & Family A: sister of P9; sister in law of $\mathrm{P} 10$ & 1 \\
\hline P3 & 26 & Female & Affected (medication) & Non & 3 \\
\hline P4 & 49 & Female & Affected (medication) & Non & 4 \\
\hline P5 & 49 & Male & Affected (liver transplantation) & Non & 3 \\
\hline P6 & 47 & Male & Affected (liver transplantation) & Family B: brother of P7 & 4 \\
\hline P7 & 50 & Male & Affected (liver transplantation) & Family B: brother of P6 & 7 \\
\hline P8 & 32 & Female & Affected (medication) & Non & 7 \\
\hline P9 & 43 & Male & Affected (liver transplantation) & Family A: brother of P2; married to P10 & 1 \\
\hline P10 & 36 & Female & Non-carrier & Family A: sister in law of P2; spouse of P9 & 1 \\
\hline P11 & 51 & Female & Affected (liver transplantation) & Family C: mother of P14 and P17 & 2 \\
\hline P12 & 52 & Female & Affected (liver transplantation) & Family D: sister of P13; cousin of P18 & 6 \\
\hline P13 & 42 & Female & Pre-symptomatic carrier & Family D: sister of P12; cousin of P18 & 10 \\
\hline P14 & 26 & Male & Non-carrier & Family C: son of P11 and brother of P17 & 3 \\
\hline P15 & 65 & Male & Non-carrier & Non & 4 \\
\hline P16 & 31 & Female & Pre-symptomatic carrier & Non & 4 \\
\hline P17 & 18 & Male & Unknown & Family C: son of P11 and brother P14 & 3 \\
\hline P18 & 47 & Female & Non-carrier & Family D: cousin of P12 and P13 & 9 \\
\hline
\end{tabular}


The interview was completed by asking questions that went into more detail in terms of the initial invitation: detailed description of the event, who was present, and what was more relevant, significant and/or meaningful. At the end, the following data were collected from the participants/narrators, for both older and young protagonists: sociodemographic (age, gender and academic status), disease status (non-carrier, pre-symptomatic carrier, affected carrier) and treatment modalities for the affected participants (no treatment, liver transplantation and oral medication), and kinship. The recruitment stopped at 18 participants (76 critical incidents; 3 participants related 1 incident-minimum; and 1 recounted 10-maximum; mean of 4.3 incidents per participant) (Table 1), which was when the authors agreed that theoretical saturation (situation where the data became redundant) had been reached. ${ }^{24}$ The saturation point was determined by using the agreement of the inter-judges in the following manner: the first author, who conducted and transcribed the interviews, announced that saturation had been reached, then the other two authors read the transcripts of the interviews independently and indicated their agreement. The average duration of the interviews was $25 \mathrm{~min}$, ranging from 10 to $49 \mathrm{~min}$.

\section{Sample}

The sample comprises 18 participants (narrators of the incidents), 10 of which are women (Table 1 ). The ages range from 18 to 65 years (mean $=42$ years). In relation to the academic status, the following was observed: 1-4 years of schooling, $n=1$; 5-9 years of schooling, $n=10$; $10-12$ years, $n=4$; university degree, $n=2$ ( 1 missing value).

The 18 participants are members of 11 families; 7 participants do not have family relationships within the sample, while 11 participants are members of 4 families. Regarding the disease status, the data show that 11 participants are affected ( 8 with liver transplantation and 3 with oral medication), 2 are presymptomatic carriers, 4 are non-carriers and 1 has an unknown illness status (has not undergone PST). The participants tend to be the younger protagonist (64 incidents; $84.2 \%$ ), less frequently are the older protagonist (11 incidents; $14.5 \%)$, and in one event is a witness.

\section{Data analysis}

Interviews were audio-taped, transcribed in full and the critical incidents submitted for content analysis by the first and third authors. The two coders started by reading all of the incidents. After the process of content analysis had been conducted comprising two stages: the definition of the categories of the older family members' roles and the classification of incidents into these categories. The initial stage of analysis aimed to define categories, and the creation and testing of the categorisation system was an iterative process of successive refinement that involved two independent coders. Each coder read all of the incidents and developed a list of categories and subcategories. Both coders then met in order to compare and discuss their proposals until agreement was reached. Lastly, each coder randomly categorised five incidents in order to confirm that the categorisation system fitted the episodes. The list of categories and subcategories were organised along with a definition and criteria for assignment plus an example of incidents that would fit the category. In a second phase, the two coders independently categorised the incidents. After each coder had independently analysed all of the incidents, they met and registered their agreements as well as their disagreements. The inter-judgment agreement (this score was reached by dividing the number of agreements by the total number of agreements plus disagreements) was $81.6 \%$, indicating a quite high reliability. ${ }^{25}$ Finally, the two coders discussed the incidents on which they disagreed, and this discussion led to the total agreement on all of the incidents. After this, the analysis focused on the intergenerational flow. Hence, for each critical incident the older and younger protagonists were identified, and kinship, sociodemographic data (gender, age) and disease status were obtained. Then cross-tabulations were calculated to depict the number of times each of the possible variables combinations occurred in the incidents.

\section{RESULTS}

The obtained results indicate four categories of roles played by the older family members regarding their younger relatives (Table 2): 'Modelling health-related behaviour' (52.6\%), '(Not) Encouraging to
Table 2 Roles played by the older generation towards the younger generation in families with FAP

\begin{tabular}{lc}
\hline Categories and subcategories & 76 Incidents \\
\hline Modelling health-related behaviours & $40(52.6 \%)$ \\
Normalising the illness experience & $19(25 \%)$ \\
Living transmitters of the disease experience & $17(22.4 \%)$ \\
Dramatising the illness experience & $4(5.3 \%)$ \\
(Not) Encouraging to carry out the pre-symptomatic test (PST) & $14(18.4 \%)$ \\
Encouraging & $6(7.9 \%)$ \\
Supporting any decision & $3(3.9 \%)$ \\
Providing practical support & $3(3.9 \%)$ \\
Discouraging & $2(2.6 \%)$ \\
Supporting & \\
Emotional support (carrier PST result) & $12(15.8 \%)$ \\
Advising on personal life decisions & $4(5.3 \%)$ \\
Emotional and instrumental support during the disease & $3(3.9 \%)$ \\
Supporting the decision of undergoing the available treatments & $3(3.9 \%)$ \\
(Not) Informing of the (risk of) disease & $2(2.6 \%)$ \\
Informing & \\
Motivating the search for disease-related information & $10(13.2 \%)$ \\
Silencing & $5(6.6 \%)$ \\
\hline
\end{tabular}

carry out the PST' (18.4\%), 'Supporting' (15.8\%) and '(Not) Informing of the risk of disease' (13.2\%).

The modelling category comprises events in which the older persons influence the younger ones by their own example and, at least apparently, without intention. It contains three subcategories: 'Normalising the illness experience' (25\%) that describes situations where the older protagonists that are affected continue to care for themselves and still support and worry about others in the family; 'Dramatising the illness experience' $(5.3 \%)$ that includes episodes where the older protagonists that are affected show despair and the desire to die; 'Living transmitters of the disease experience' (22.4\%) that comprises events where members of the younger generation observe in the older affected relatives the symptoms and their progression, and the attached suffering.

The category on encouraging involves episodes where the older family members influence their younger relatives regarding the performance or not of the PST. It entails of four subcategories: 'Encouraging' (7.9\%), which consists in persuading and even pressuring the young individuals to carry out the PST; 'Supporting any decision' (3.9\%)—do it, don't do it, or delay the decision; 'Providing practical support' regarding the process of PST (eg, scheduling and going with the individual to the consultations and/or receiving the PTS results); 'Discouraging' doing the PST (2.6\%), usually in an implicit way, this is, the older family members postpone any attempt of the younger members to discuss the topic or simply ignore their search for information.

The supporting category takes four subcategories into account: 'Emotional support' (5.3\%) when the result of the PST is positive (carrier), usually by giving hope to the younger relative, which is associated to the new available treatments; "Advising on personal life decisions' $(3.9 \%)$, typically the older protagonist advise the carriers to not have children and to warn the non-carriers about a possible relationship or marriage with a carrier; 'Emotional and instrumental support during the disease' $(3.9 \%)$ that implies taking the younger 
affected relatives to consultations, preparing their meals and generally showing empathy; 'Supporting the decision of undergoing the available treatments' $(2.6 \%)$ that entails the encouragement and motivation of younger individuals to not give up.

The category related to information comprises events where the older family members transmit, or do not transmit, information to the younger generation on the disease and its possible treatments and/or motivate them to search for (more) information. It encompasses three subcategories: 'Informing' (6.6\%), which occurs when the older family members transmit what they know about the disease (eg, history in the family, characteristics of the disease and old myths); 'Motivating the search for disease-related information' (5.3\%) that report situations where the older generation motivate, support and collaborate with the younger generation in order for them to get more information and experience regarding the disease (eg, participating in conferences, searching for information on the Internet and talking to affected persons outside of the family unit); and 'Silencing' (1.3\%) that refers a situation where the old individual even when directly questioned did not talk about the disease.

The next step was to carry on the cross-tabulations, starting with the gender of the older and younger protagonists of the incidents. The older protagonist in 52 incidents $(68.4 \%)$ is a female; and the younger protagonist is in 46 incidents $(60.5 \%)$ also a female. Data show that the flow of the intergenerational transmission occurs mostly between females (34 incidents), or from older females to younger males (18 incidents); some events from older males to younger females (12 incidents) and between males (12 incidents).

Then the same procedure was performed regarding kinship between older and younger protagonists (Table 3). The kinship of the older family members with the younger ones involves mostly mothers (41 incidents) and fathers (16 incidents). Concomitantly, the affinity of the younger family members with the older ones is mostly daughter (33 incidents) and son (24 incidents). The most frequent associations are mother and daughter (25 incidents); mother and son (16 incidents); father and daughter ( 8 incidents); father and son (8 incidents); and also aunt and niece (7 incidents).

In terms of the disease status, the most frequent links involve (Table 3): older family members affected and younger members with an unknown illness status (28 incidents); older family members affected and younger members who are also affected (12 incidents); older family members affected and non-carrier younger family members (8 incidents); and older non-carriers and younger affected family members (6 incidents).

Then the analysis focused on the association between the role played by the older generation and the kinship between old and young protagonists (Table 4). Data show that the mother plays the modelling role mainly towards her children (daughter and son); in terms of subcategories, mothers are mostly living transmitters of the disease experience (12 incidents) and normalise the illness experience (10 incidents). The father tends to play the following roles towards his children (son and daughter): modelling, mostly by normalising the illness experience ( 5 incidents); informing, mostly by motivating the search for disease-related information (3 incidents); and encouraging to carry out the PST (3 incidents). Data also indicate that the aunts/ uncles tend to assume roles towards nieces/nephews that are similar to those played by the mothers towards their children, this is, modelling by being living transmitters of the disease experience ( 5 incidents) and by normalising the illness experience ( 4 incidents).

Finally, the roles played by the older generation of the family towards the younger generation was analysed considering the disease status (Table 4). The older affected protagonists mainly play the
Table 3 Older and younger protagonists: kinship disease status

\begin{tabular}{ll} 
Kinship from older to $(\rightarrow)$ young $(n)$ & Disease status from older to $(\rightarrow)$ young $(n)$ \\
\hline Mother $\rightarrow$ Daughter (25) & Affected $\rightarrow$ Unknown (28) \\
Mother $\rightarrow$ Son (16) & Affected $\rightarrow$ Pre-symptomatic (12) \\
Father $\rightarrow$ Daughter (8) & Affected $\rightarrow$ Non-carrier (8) \\
Father $\rightarrow$ Son (8) & Affected $\rightarrow$ Affected (6) \\
Aunt $\rightarrow$ Niece (7) & Non-carrier $\rightarrow$ Affected (6) \\
Aunt $\rightarrow$ Nephew (1) & Non-carrier $\rightarrow$ Unknown (4) \\
Uncle $\rightarrow$ Niece (3) & Non-carrier $\rightarrow$ Pre-symptomatic (4) \\
Uncle $\rightarrow$ Nephew (1) & Non-carrier $\rightarrow$ Non-carrier (4) \\
Grandmother $\rightarrow$ Grandson (2) & Pre-symptomatic $\rightarrow$ Unknown (2) \\
Grandmother $\rightarrow$ Granddaughter (1) & Unknown $\rightarrow$ Pre-symptomatic (1) \\
Grandfather $\rightarrow$ Grandson (2) & Unknown $\rightarrow$ Affected (1) \\
Female cousin $\rightarrow$ Female cousin (1) & \\
Male cousin $\rightarrow$ Female cousin (1) & \\
\hline
\end{tabular}

following roles towards the younger protagonists: modelling by normalising the illness experience, mostly towards members of the younger generation that are non-carriers (6 incidents) and affected (5 incidents); modelling by being living transmitters of the disease experience towards those young protagonists that still do not know their genetic status (12 incidents); encouraging to carry out the PST towards those that still do not know their genetic status (4 incidents). Furthermore, results indicate that the older family members that are non-carriers tend to assume the following roles: modelling, mostly by normalising the illness experience towards the younger protagonists that are non-carriers (2 incidents), affected (1 incident) and presymptomatic carriers ( 1 incident); supporting the younger protagonists that are affected, mostly through emotional and practical support during the disease ( 3 incidents) and supporting the decision to undergo the available treatments ( 2 incidents).

\section{DISCUSSION}

The main findings of this study suggest that the intergenerational flow takes place mostly between women, from mother to daughter, and from older affected persons to young pre-symptomatic carriers. Data also suggest that the older generation in FAP families play four main roles towards their younger counterparts: modelling, encouraging, supporting and informing. ${ }^{26}$ Similar roles have been suggested in previous studies that mostly focus on hereditary cancers. ${ }^{7,12,27,28}$ The most frequent role is modelling, mostly by normalising the experience of the illness and by being a living transmitter of the disease experience (dramatising is less frequent). Modelling emerges as a role performed unintentionally, that is, normalising the experience of the illness is performed by being an example and by being a living transmitter of the disease because the younger generation tend to observe the behaviour of the older generation. Moreover, normalising the illness experience helps the younger subjects to 'put the illness in its place', ${ }^{29}$ which means that they learn or better understand that it is possible to manage and make the disease compatible with other family, social and/or professional functions. The role of living transmitter of the disease experience helps the younger individuals to better comprehend what it is like to live with the disease in terms of symptoms, incapacity and suffering. It is probable that the older persons realise that even without a clear intention, they are influencing their younger relatives to understand what the disease is and are normalising their experience of living with the illness. This will most likely help the older persons achieve an integrity that is associated with the building of a legacy that 
Table 4 Roles played by the older family members regarding the younger: kinship and disease status

\begin{tabular}{|c|c|c|}
\hline Roles & Kinship from older to $(\rightarrow)$ young $(n)$ & Disease status from older to $(\rightarrow)$ young $(n)$ \\
\hline \multicolumn{3}{|l|}{ Modelling health-related behaviours } \\
\hline \multirow[t]{7}{*}{ Normalising } & Mother $\rightarrow$ Children (10) & Affected $\rightarrow$ Non-carrier $(6)$ \\
\hline & Father $\rightarrow$ Children (5) & Affected $\rightarrow$ Pre-symptomatic (5) \\
\hline & Uncles $\rightarrow$ Nephews (4) & Affected $\rightarrow$ Affected (3) \\
\hline & & Non-carrier $\rightarrow$ Non-carrier (2) \\
\hline & & Non-carrier $\rightarrow$ Affected $(1)$ \\
\hline & & Non-carrier $\rightarrow$ Pre-symptomatic (1) \\
\hline & & Affected $\rightarrow$ Unknown (1) \\
\hline \multirow[t]{4}{*}{ Living transmitter } & Mother $\rightarrow$ Children (12) & Affected $\rightarrow$ Unknown (12) \\
\hline & Uncles $\rightarrow$ Nephews (5) & Affected $\rightarrow$ Non-carrier (2) \\
\hline & & Affected $\rightarrow$ Pre-symptomatic (2) \\
\hline & & Affected $\rightarrow$ Affected $(1)$ \\
\hline \multirow[t]{3}{*}{ Dramatising } & Mother $\rightarrow$ Children (3) & Affected $\rightarrow$ Pre-symptomatic (2) \\
\hline & Uncles $\rightarrow$ Nephews (1) & Affected $\rightarrow$ Unknown (1) \\
\hline & & Unknown $\rightarrow$ Pre-symptomatic (1) \\
\hline \multicolumn{3}{|c|}{ (Not) Encouraging to carry out the PTS (pre-symptomatic genetic test) } \\
\hline \multirow[t]{3}{*}{ Encouraging } & Mother $\rightarrow$ Children $(3)$ & Affected $\rightarrow$ Unknown (4) \\
\hline & Father $\rightarrow$ Children (3) & Non-carrier $\rightarrow$ Unknown $(1)$ \\
\hline & & Pre-symptomatic $\rightarrow$ Unknown (1) \\
\hline \multirow[t]{2}{*}{ Supporting any decision } & Mother $\rightarrow$ Children (2) & Affected $\rightarrow$ Unknown (3) \\
\hline & Father $\rightarrow$ Children $(1)$ & \\
\hline \multirow[t]{2}{*}{ Practical support } & Grandparent $\rightarrow$ Grandchildren (2) & Non-carrier $\rightarrow$ Unknown (2) \\
\hline & Uncles $\rightarrow$ Nephews (1) & Affected $\rightarrow$ Unknown (1) \\
\hline Discouraging & Mother $\rightarrow$ Children (2) & Affected $\rightarrow$ Unknown (2) \\
\hline \multicolumn{3}{|l|}{ Supporting (carriers) } \\
\hline \multirow[t]{3}{*}{ Emotional (carrier test result) } & Mother $\rightarrow$ Children (2) & Non-carrier $\rightarrow$ Pre-symptomatic (2) \\
\hline & Father $\rightarrow$ Children $(1)$ & Affected $\rightarrow$ Pre-symptomatic (2) \\
\hline & Grandparent $\rightarrow$ Grandchildren (1) & \\
\hline \multirow[t]{3}{*}{ Advising (personal life) } & Mother $\rightarrow$ Children $(1)$ & Non-carrier $\rightarrow$ Non-carrier $(1)$ \\
\hline & Father $\rightarrow$ Children (1) & Non-carrier $\rightarrow$ Pre-symptomatic (1) \\
\hline & Uncles $\rightarrow$ Nephews $(1)$ & Affected $\rightarrow$ Pre-symptomatic (1) \\
\hline \multirow[t]{2}{*}{ Emotional and instrumental (affected) } & Mother $\rightarrow$ Children (2) & Non-carrier $\rightarrow$ Affected (3) \\
\hline & Father $\rightarrow$ Children (1) & \\
\hline Decisions on treatments & Father $\rightarrow$ Children (2) & Non-carrier $\rightarrow$ Affected (2) \\
\hline \multicolumn{3}{|l|}{ (Not) Informing of the (risk of) disease } \\
\hline \multirow[t]{4}{*}{ Informing } & Mother $\rightarrow$ Children (3) & Affected $\rightarrow$ Unknown (2) \\
\hline & Cousin $\rightarrow$ Cousin $(2)$ & Non-carrier $\rightarrow$ Non-carrier $(1)$ \\
\hline & & Affected $\rightarrow$ Affected $(1)$ \\
\hline & & Unknown $\rightarrow$ Affected $(1)$ \\
\hline \multirow[t]{2}{*}{ Motivating } & Father $\rightarrow$ Children $(3)$ & Non-carrier $\rightarrow$ Unknown (2) \\
\hline & Mother $\rightarrow$ Children $(1)$ & Affected $\rightarrow$ Unknown (2) \\
\hline Silencing & Mother $\rightarrow$ Children $(1)$ & Affected $\rightarrow$ Affected $(1)$ \\
\hline
\end{tabular}

will shape the way they will be remembered by the younger generation. ${ }^{16,30}$

The role of encouraging is mainly associated with the carrying out of the PST. In fact, the older protagonists that assume this role seem to consider that, for the younger individual, it is decisive to know their disease status because it will determine their health management and decisions in family life (such as the decision to have children or not). Additionally, the older generation tends to encourage the younger generation to carry out the PST. Nevertheless, some choose to support any decision taken by the younger generation and a few others opt to discourage the performance of the PST.

Supporting is a role that the older persons assume when the younger family members are confronted with the carrier result in the
PST and during the chronic phase of the disease. This role has emerged also in the literature on intergenerational relationships and hereditary diseases, ${ }^{12,27}$ which emphasises that older persons tend to receive care from the younger persons. Yet, when the younger relatives are in need and the older persons are still independent, they assume the role of informal caregivers. This role underlines the families adaptive capacity, that is necessary when severe problems exist, and the reciprocity and mutuality that depicts intergenerational relationships. $^{16}$

The role of informing about the disease or the risk of having the disease is less frequent, and has emerged in the literature on hereditary diseases to describe that the older family members disseminate the family health history. ${ }^{7,8,12,17,27}$ The older relatives have a lived and 
non-documented experience about the disease, have deceased relatives and also family, community and social stories and myths regarding the condition. These roles seem to be assumed more explicitly, but performed with diversity: some members of the older generation choose to share what they know and/or motivate the younger subject to get (more) information. However, some others may decide to keep silent, which may be due to the associated suffering when remembering experiences related to the disease. Research, mostly with hereditary cancers, has shown similar findings. ${ }^{14,27,31}$

In terms of the flow of the intergenerational roles, data suggest that this mostly arises from older to younger women. Therefore, it seems that women from the older generation influence those from the younger generation, and as some literature has already suggested, women are gatekeepers and the dominant gender in the context of exchanging health information within the family. ${ }^{7,9}$ This result is consistent with the traditional description of gender roles in families and also with the adopted family dynamics when faced with chronic severe diseases. ${ }^{29}$ Moreover, while men tend to assume more instrumental and external roles, women perform more emotional and expressive functions, which they tend to keep within the family unit. $^{10,18}$

This study shows that mothers play their roles mostly towards their daughters (less frequently, towards their sons) in terms of modelling their children's experience of the disease (living transmitter of the disease and normalising the experience of the illness). And, fathers perform their role towards their daughters and/or sons by mostly assuming the role of modelling, but also informing and encouraging. The available literature has suggested that intergenerational influencing strategies have gender differences: women tend to influence most at an emotional level, while men exert their influence by being problem oriented. ${ }^{10,18,29}$ Thus, the exercise of the roles tends to occur from parents to children, that is, between contiguous consanguineous generations. ${ }^{28}$ However, also some roles performed by aunts/uncles towards nieces/nephews sometimes emerge, and are aligned with the roles performed by the mothers towards their sons/daughters: modelling health-related behaviours by being living transmitters of the disease experience and normalising the illness experience. It is probable that this type of influence takes place because the parents are unable to exert their family roles due to impairments related to the disease.

Furthermore, the results suggest that the roles played by the older generation differ considering the disease status. The influence of older family members that are affected was the most frequent, possibly because as they are experiencing the disease, they model the behaviour of the younger family members that still do not know their genetic status; hence disclosing what it is like to live with the disease (living transmitters) and, implicitly, influencing the younger relatives to make decisions regarding the PST. The older family members that are affected also influence the pre-symptomatic carriers by helping them to understand the disease and by showing them how it can be faced, thus normalising the illness experience. The older family members that are non-carriers tend to assume other roles. They also fall into the category of modelling by normalising the illness experience towards the younger generation that are non-carriers, affected or presymptomatic carriers, but mostly the older generation that are noncarriers assume the role of supporting (emotionally and instrumentally) and encouraging (to undergo the available treatments) the younger generation that are affected.

The results of this study suggest that the older generation in FAP families play relevant roles in terms of promoting health behaviours and risk management towards their younger relatives. As FAP represents a public health problem in the high prevalence clusters, clinical genetic services and the health-care system more broadly might want to consider these roles and the intergenerational flow so that this information can be used to enhance health promotion behaviours in at-risk families.

\section{Limitations and further research perspectives}

The main limitation of this study was the reduced size of the sample (18 participants) despite the data saturation. In addition, the sample comprises mainly family members from the intermediate generation (most participants were 31-52 years old). A larger sample with more participants from older and younger generations would have allowed a better understanding of the roles performed by the older family members as well as the intergenerational transmission flow. In addition, since inherited disorders are a family matter, future studies could explore in/congruencies within each family, to highlight individual perspectives within families, and how they might be interacting and influencing health-related behaviours. Also, future research could include the perspective of family members that choose not to carry out the PST in order to explore the type of influence this decision has. Upcoming studies could also explore the evolving role of the older persons as new and more efficient treatments are made available. Furthermore, coming studies should examine the professionals' perspectives on the roles of the older family members. And also examine the role of the older generation in other genetically inherited diseases.

\section{CONFLICT OF INTEREST}

The authors declare no conflict of interest.

\section{ACKNOWLEDGEMENTS}

The authors are indebted to all the participants in this study, for sharing their time and experience. The authors thank the APP, especially to Sandra Costa, for help in the recruitment of the participants. Álvaro Mendes is the recipient of a postdoctoral grant from FCT (the Portuguese Foundation for Science and Technology; SFRH/BPD/88647/2012). This article was supported by FEDER through the operation POCI-01-0145-FEDER-007746 funded by the Programa Operacional Competitividade e Internacionalização-COMPETE2020 and by National Funds through FCT-Fundação para a Ciência e a Tecnologia within CINTESIS, R\&D Unit (reference UID/IC/4255/2013).

1 Adams D, Suhr OB, Hund E et al: First European consensus for diagnosis, management, and treatment of transthyretin familial amyloid polyneuropathy. Curr Opin Neurol 2016; 29: S14-S26.

2 Andrade C: A peculiar form of peripheral neuropathy. Brain 1952; 75: 408-427.

3 Sousa A: Epidemiologia genética da polineuropatia amiloidótica familiar. Sinapse 2006; 6: 74-79.

4 Sequeiros J: Protocolo geral do programa nacional de teste preditivo e aconselhamento genético na doença de Machado-Joseph. In Sequeiros J (ed.) O Teste Preditivo da Doença de Machado-Joseph. Porto: UnIGENe, IBMC, 1996; pp 123-149.

5 Carvalho F: Preimplantation genetic diagnosis for TTR-FAP in Portugal. Orphanet J Rare Dis 2015; 10: 15.

6 Mendes Á, Paneque M, Sousa L, Clarke A, Sequeiros J: How communication of genetic information within the family is addressed in genetic counselling. Eur J Hum Genet 2016; 24: 315-325.

7 Koehly LM, Peters JA, Kenen $R$ et al: Characteristics of health information gatherers, disseminators, and blockers within families at risk of hereditary cancer: Implications for family health communication interventions. Am J Public Health 2009; 99: 2203-2209.

8 Mendes Á, Sousa L: Families' experience of oncogenetic counselling: accounts from a heterogeneous hereditary population. Fam Cancer 2012; 11: 291-306.

9 Palmquist AEL, Koehly LM, Peterson SK, Shegog M, Vernon SW, Gritz ER: «The cancer bond»: exploring the formation of cancer risk perception in families with Lynch syndrome. J Genet Couns 2010; 19: 473-486.

10 Christophe V, Vennin P, Corbeil M, Adenis C, Reich M: Social sharing of genetic information in the family. J Health Psychol 2009; 14: 855-860. 
11 Ersig AL, Williams JK, Hadley DW, Koehly LM: Communication, encouragement, and cancer screening in families with and without mutations for hereditary nonpolyposis colorectal cancer: a pilot study. Genet Med 2009; 11: 728-734.

12 Ashida S, Schafer EJ: Family health information sharing among older adults: reaching more family members. J Community Genet 2015; 6: 17-27.

13 Rodríguez VM, Corona R, Bodurtha JN, Quillin JM: Family ties: the role of family context in family health history communication about cancer. J Health Commun 2016; 21: 346-355.

14 Hovick SR, Yamasaki JS, Burton-Chase AM, Peterson SK: Patterns of family health history communication among older African American adults. J Health Commun 2015; 20: $80-87$

15 Theurer K, Wister A: Altruistic behaviour and social capital as predictors of well-being among older Canadians. Ageing Soc 2010; 30: 157-181.

16 Guerra S, Figueiredo D, Patrão M, Sousa L: Family integrity among older caregivers of relatives with dementia. Paidéia 2016; 26: 15-23.

17 Ashida S, Wilkinson AV, Koehly LM: Motivation for health screening: evaluation of social influence among Mexican-American. Am J Prev Med 2010; 38: 396-402.

18 Warren-Findlow J, Seymour RB, Shenk D: Intergenerational transmission of chronic illness self-care. Gerontologist 2011; 51: 64-75.

19 Flanagan JC: The critical incident technique. Psychol Bull 1954; 51: 327-358.

20 Tripp D: Critical Incidents in Teaching. London: Routledge, 1993.

21 Sousa L: Beliefs and values of family doctors and multi-problem poor clients. Quality in Primary Care 2007; 15: 277-283.
22 Schluter J, Seaton P, Chaboyer W: Critical incident technique. J Adv Nurs 2008; 61: 107-114.

23 Warren-JL, Miller K, Warren A: African American women's retrospective perceptions of the intergenerational transfer of gynecological health care information received from mothers. J Fam Commun 2010; 10: 81-98.

24 Mason M: Sample size and saturation in $\mathrm{PhD}$ studies using qualitative interviews. Forum Qual Soc Res 2010. Available at: http://nbn-resolving.de/urn:nbn:de:0114fqs100387.

25 Miles MB, Huberman AM: Qualitative Data Analysis. California: SAGE, 1984.

26 Oliveira C, Mendes Á, Sousa L: Promoção da saúde em famílias com paramiloidose: papéis dos mais velhos junto dos mais novos 2017; Cad Saúde Pública (accepted).

27 Ashida S, Hadley D, Goergen A, Skapinsky K, Devlin H, Koehly LM: The importance of older family members in providing social resources and promoting cancer screening in families with a hereditary cancer. Gerontologist 2011; 51: 833-842.

28 Mendes Á: Doenças hereditárias, aconselhamento genético e redes familiares e sociais Rev Kairos 2012; 15: 199-216.

29 Gonzalez S, Steinglass P, Reiss D: Putting the illness in its place: discussion groups for families with chronic medical illnesses. Fam Process 1989; 28: 69-87.

30 Sousa L, Patrão M, Mendes Á: Material inheritances: an affective story in the history of elderly persons. Intern J Ageing Later Life 2015; 9: 35-52.

31 Yamasaki J, Hovick SR: "That was grown folks' business»: narrative reflection and response in older adults' family health history communication. Health Commun 2015; 30: 221-230. 